\title{
Model-based evaluation of the genetic impacts of farm-escaped Atlantic salmon on wild populations
}

\author{
Ian R. Bradbury ${ }^{1, *}$, Steve Duffy ${ }^{1}$, Sarah J. Lehnert ${ }^{1}$, Ragnar Jóhannsson $^{2}$, \\ Jon Hlodver Fridriksson ${ }^{2}$, Marco Castellani ${ }^{3}$, Ingrid Burgetz ${ }^{4}$, Emma Sylvester ${ }^{1}$, \\ Amber Messmer ${ }^{1}$, Kara Layton ${ }^{1}$, Nicholas Kelly ${ }^{1}$, J. Brian Dempson ${ }^{1}$, Ian A. Fleming ${ }^{5}$ \\ ${ }^{1}$ Science Branch, Fisheries and Oceans Canada, 80 East White Hills Rd., St. John's, NL A1C 5X1, Canada \\ ${ }^{2}$ Marine and Freshwater Research Institute, Skulagata 4, 101 Reykjavik, Iceland \\ ${ }^{3}$ Department of Mechanical Engineering, University of Birmingham, Birmingham B15 2TT, UK \\ ${ }^{4}$ Fisheries and Oceans Canada, 200 Kent Street Ottawa, ON K1A 0E6, Canada \\ ${ }^{5}$ Department of Ocean Sciences, Memorial University of Newfoundland, St. John's, NL A1C 5S7, Canada
}

\begin{abstract}
Genetic interactions (i.e. hybridization) between wild and escaped Atlantic salmon Salmo salar from aquaculture operations have been widely documented, yet the ability to incorporate predictions of risk into aquaculture siting advice has been limited. Here we demonstrate a model-based approach to assessing these potential genetic interactions using a salmon aquaculture expansion scenario in southern Newfoundland as an example. We use an eco-genetic individualbased Atlantic salmon model (IBSEM) parameterized for southern Newfoundland populations, with regional environmental data and field-based estimates of survival, to explore how the proportion of escapees relative to the size of wild populations could potentially influence genetic and demographic changes in wild populations. Our simulations suggest that both demographic decline and genetic change are predicted when the percentage of escapees in a river relative to wild population size is equal to or exceeds $10 \%$ annually. The occurrence of escapees in southern Newfoundland rivers under a proposed expansion scenario was predicted using river and site locations and models of dispersal for early and late escapees. Model predictions of escapee dispersal suggest that under the proposed expansion scenario, the number of escapees is expected to increase by $49 \%$ and the highest escapee concentrations will shift westward, consistent with the location of proposed expansion ( 20 rivers total $>10 \%$ escapees, max $24 \%$ ). Our results identify susceptible rivers and potential impacts predicted under the proposed aquaculture expansion scenario and illustrate how model-based predictions of both escapee dispersal and genetic impacts can be used to inform both aquaculture management decisions and wild salmon conservation.
\end{abstract}

KEY WORDS: Hybridization - Atlantic salmon - Aquaculture $\cdot$ Management $\cdot$ Newfoundland

\section{INTRODUCTION}

Genetic interactions (i.e. hybridization) between wild and escaped Atlantic salmon Salmo salar from aquaculture operations have been documented across the natural range of the species where the 2 co-occur (Glover et al. 2017, Keyser et al. 2018). Escaped farmed Atlantic salmon regularly occur in both Europe and Atlantic Canada (Keyser et al. 2018,

${ }^{*}$ Corresponding author: ibradbur@me.com
Diserud et al. 2019, Glover et al. 2019) and have been commonly found in rivers at distances of up to $200 \mathrm{~km}$ from the nearest aquaculture site, although distant occurrences at sea have also been reported (Hansen et al. 1993, 1997, Hansen \& Jacobsen 2003, Jensen et al. 2013). As a consequence, hybridization between wild and domestic salmon can be both spatially extensive and represent a significant proportion of a population's annual production (Glover et al. 2013,

() R, Jóhannsson, J. H. Fridriksson, M. Castellani, I. A. Fleming and Fisheries and Oceans Canada 2020. Open Access under Creative Commons by Attribution Licence. Use, distribution and reproduction are unrestricted. Authors and original publication must be credited.

Publisher: Inter-Research · www.int-res.com 
2017, Karlsson et al. 2016, Sylvester et al. 2018, Wringe et al. 2018). Both experimental and field studies have demonstrated decreased survival of hybrids in the wild (Fleming et al. 2000, McGinnity et al. 2003, Sylvester et al. 2019), and suggest that wild population decline and genetic change are the likely outcomes of hybridization and introgression (Hindar et al. 2006, Castellani et al. 2015, 2018, Sylvester et al. 2019). As a result, genetic interactions with escaped farmed salmon have been identified as a significant threat to the persistence and stability of wild Atlantic salmon populations (Forseth et al. 2017).

In Atlantic Canada, Atlantic salmon aquaculture escapees (Morris et al. 2008, Keyser et al. 2018) and hybridization with wild individuals have been observed throughout the region (O'Reilly et al. 2006, DFO 2018a, Sylvester et al. 2018, Wringe et al. 2018). In particular, recent studies have documented widespread hybridization between wild salmon and aquaculture escapees following a single escape event that occurred in 2013 in southern Newfoundland (Wringe et al. 2018). Model-based projections following this escape event using cohort-based estimates of survival suggest negative impacts on population productivity and genetic integrity (Sylvester et al. 2019). These results are consistent with evidence of genetic changes in wild Norwegian salmon populations, which show levels of introgression as high as $47 \%$ (Karlsson et al. 2016), reductions in productivity (Fleming et al. 2000, Skaala et al. 2019), and changes in key life history traits (Bolstad et al. 2017). In Atlantic Canada, Atlantic salmon aquaculture expansion has been proposed for several regions, including those with threatened or at-risk wild salmon populations. Salmon populations in the Bay of Fundy, eastern Nova Scotia, and southern Newfoundland have been classified as threatened or endangered by the Committee on The Status of Endangered Wildlife In Canada (COSEWIC 2010), with many populations at record lows of abundance (DFO 2018a, b, 2019). Accordingly, there is a pressing need to develop approaches to predict the genetic impacts of salmon net-pen aquaculture on wild populations for use in aquaculture management and spatial planning.

Model-based approaches to explore escape events from net-pens and their impacts on wild populations allow the opportunity to evaluate escape scenarios and management decisions and are currently under development for salmonids as well as other marine species (e.g. Baskett et al. 2013). For Atlantic salmon, several models of genetic and demographic interactions among wild and farm escapees have been developed and applied, including OMEGA (ICF Inter- national 2012), IBSEM (Castellani et al. 2015), and that of Hindar et al. (2006). Of these, IBSEM, an individual-based eco-genetic Atlantic salmon life history model, has been most extensively used. Applications include understanding how the proportion of escapees scales with demographic and genetic impacts in Norway (Castellani et al. 2015, 2018), how natural straying may mitigate these impacts (Castellani et al. 2018), and how varying the strength of selection against offspring of aquaculture escapees in the wild influences population outcomes (Sylvester et al. 2019). In addition to these modeling efforts, a recent study has modeled the escape, dispersal, and survival of escapees from release sites to wild rivers in Iceland (e.g. Johannsson et al. 2017).

The combination of model-based estimates of impact with empirical data provides an unprecedented opportunity to inform management and policy decisions related to genetic outcomes for populations affected by escaped farmed Atlantic salmon. Consequently, the goal of this study was to illustrate the potential for model-based approaches to (1) predict genetic and demographic change as a result of escapees under a proposed Atlantic salmon aquaculture expansion scenario and (2) to contribute to aquaculture siting and management decisions. Specifically, the population impacts (i.e. demographic and genetic) of farm escapees were examined using IBSEM, parameterized for southern Newfoundland populations (Castellani et al. 2015, 2018). To further illustrate potential applications to siting and risk assessment, we modeled the distribution of escapees in the wild prior to and following an aquaculture expansion scenario in southern Newfoundland using a spatial model of dispersal and survival recently implemented in Iceland (Johannsson et al. 2017). This study builds directly on modeling and empirical studies from across Canada and Europe (Castellani et al. 2015, 2018, Johannsson et al. 2017, Sylvester et al. 2019) and demonstrates how consideration of genetic impacts of escapees on wild salmon populations may be incorporated into management decisions.

\section{METHODS}

\subsection{Individual-based modeling of direct genetic impacts}

Detailed modeling methods using IBSEM are described in Castellani et al. $(2015,2018)$ and Sylvester et al. (2019). IBSEM models wild population changes in abundance, genotype, and individual size in 
response to the introduction of domesticated individuals. The model considers the duration of invasion, wild population size, number of invaders, environmental conditions, individual size, and genotypic and phenotypic differences between individuals of farm and wild origin. Growth and survival are simulated by stochastic processes that are influenced by genotype, fish size and age, water temperature, and population density at 3 life stages: embryo, juvenile, and adult. Simulated loci are unlinked with possible gamete recombination and random inheritance, and have a range of influences on phenotype and therefore performance in the environment. The sum of the genetic effects is linearly related to phenotype, such that genotypic values approaching 1 are associated with growth and survival rates typical of wild salmon, and values approaching 0 are associated with rates observed in farm escapees. Reproductive success of farm escapees is reduced relative to wild salmon, and the success of both is sex-specific, with female fertility dependent upon weight and male reproductive success dependent upon length, with the possibility of precocial sexual maturation as parr. A full list of parameters representative of Newfoundland salmon and environmental conditions in the region can be found in Sylvester et al. (2019).

Simulations utilized estimates of feral fry and parr survival calculated from genetic analysis of individual cohorts following an escape event in southern Newfoundland in 2013 (Wringe et al. 2018, Sylvester et al. 2019). These estimates of survival are lower than most previous estimates of relative survival of feral parr (McGinnity et al. 1997, Fleming et al. 2000, McGinnity et al. 2003, Skaala et al. 2019), and increasing survival in freshwater has been shown to increase both genetic and demographic impacts (Sylvester et al. 2019). We simulated the population consequences of invasion over a $50 \mathrm{yr}$ period in a wild population of 500 individuals with the proportion of invaders varying from 0 to $100 \%$ of that of the wild population annually. The model simulates the accumulation of changes (i.e. allele frequency) over this 50 -yr period resulting from both the continual influx of escapees and any successfully returning hybrid or escapee progeny. All models were run for $100 \mathrm{yr}$ prior to invasion to ensure model stability and for $100 \mathrm{yr}$ after the 50-yr invasion period ceased. We compared the change in combined adult population abundance (both wild and escaped farmed fish) and the sum of the genetic effects across the adult set of genes included in the simulation to observe changes in the genetic fitness of the population. For each iteration, we calculated the adult population abundance or allele frequency at the end of the invasion period and compared this to the mean value (10 replicates) for the no invasion scenario at the same time point. We used the mean value for the zero-invasion scenario instead of the initial starting value for the respective scenarios because at this initial time point (start of invasion period), farmed individuals are introduced into the population and thus it does not represent a baseline value.

\subsection{Propagule pressure}

To explore the potential changes in genetic interactions between wild and domestic salmon associated with the proposed expansion scenario in Newfoundland, we calculated propagule pressure following Keyser et al. (2018) for both the existing and proposed production regimes. Propagule pressure was calculated for each river using maximum stocking allowable at an aquaculture site (number of individuals, see below), divided by the distance from the river to that site $(\mathrm{km})$, and summed across all aquaculture sites. That is:

$$
\begin{aligned}
& \text { Propagule pressure for a given river }(R)= \\
& \qquad \sum_{i, y=1}^{S} \frac{F_{i, y}}{\operatorname{LCD}\left(S_{i, y} \text { to } R\right)}
\end{aligned}
$$

where $S_{i, Y}$ represents an aquaculture site (i) in a given year $(y), R$ represents a given river, $F_{i, y}$ is the number of fish at site $S_{i}$, and LCD represents the least-cost distance function. This metric has been shown to correlate with both the occurrence of escapees and genetic interactions between wild and farm escapees in Atlantic Canada (Keyser et al. 2018).

\subsection{Dispersal modeling of escapees}

To model the distribution of farm escapees and to allow scenario testing, we applied a simple dispersal model that incorporates the best information on local levels of production, rates of escape, survival, behavior, environment, and size of wild populations. Details on the dispersal model can be found in Johannsson et al. (2017), but a summary is included below. Three main categories of data were considered. First, the production data were considered and included locations, biomass, size, age, and average proportion of escapees per unit harvest. Second, geographic factors considered include distribution of rivers along the coast, and any directionality of local currents. Finally, the model included any existing life history 
data and behavioral differences between wild and farmed salmon. Two independent models were used, one for early escapees (i.e. smolts), and one for late escapees (i.e. adults) to allow for differences in behavior and survival among life stages. The model was implemented in R ( R Development Core Team 2016) with a web-based interface.

For this analysis, we focused on 76 rivers known to have wild Atlantic salmon populations along the south coast of Newfoundland, spanning the region from Bear Cove Brook to Renews River (Fig. 1). This region has been demonstrated previously to encompass genetic impacts following escape events in the region (Keyser et al. 2018, Wringe et al. 2018). As information is generally lacking on the size of wild populations in the majority of these rivers (Porter et al. 1974, DFO 2013, 2018b), such estimates of population size were derived using an established relationship between river size and wild population size for Newfoundland following Wringe et al. (2018). River size was calculated as axial length to complete obstruction using data from Porter et al. (1974). However, as the relationship derived by Wringe et al. (2018) is based on habitat, the estimates may not reflect population declines experienced over recent decades (COSEWIC 2010, DFO 2018b) and therefore may overestimate the current population size and underestimate the proportion of escapees. In the event of any error in our initial parameters, the estimates of the proportion of escapees would be more conservative than would likely be the case in the field. Nonetheless, they represent the only available estimates of population size for most of these systems.

Reported stocking, harvest information, and licensed maximum stocking allowable from 2013 to
2017 were obtained for all existing aquaculture locations in southern Newfoundland from Aquaculture Management of Fisheries and Oceans (C. Hendry pers. comm.). For consistency among existing and proposed sites, we used the maximum licensed stocking numbers. Numbers of fish were converted to harvest biomass using an individual fish weight of $3 \mathrm{~kg}$, reducing by $25 \%$ to account for fallow periods and the production/fallow cycle, and finally multiplying by 0.65 , a ratio estimated from a comparison of stocking and harvest that excludes sites with catastrophic losses. The expected number of escapees per unit production is required to estimate escapees in the environment. In the absence of an extensive escapee monitoring program in southern Newfoundland, we rely on Norwegian statistics of annual production and escape events for the period 2009-2016 to estimate the expected number of escapees per ton of fish production (www.fiskeridir. no/English/Aquaculture/Statistics). However, these estimates of escapees have been shown to be an underestimate (Skilbrei et al. 2015, Glover et al. 2017); therefore, they were adjusted following Skilbrei et al. (2015) as per Johannsson et al. (2017). As a result, the estimate is $\sim 0.8$ fish per ton of production, but, given uncertainty in this value for Newfoundland, extensive sensitivity analyses were conducted to explore the effect of other values from 0.2 to 1.2 .

The proportion of escapees that enter estuaries and could ascend rivers was estimated to be $17 \%$ based on Hamoutene et al. (2018), with correction for estuaries without receivers. This calculation assumes all escapees detected in estuaries will enter adjacent rivers, and although it is actually unknown what proportion of escapees in estuaries will enter rivers, es-

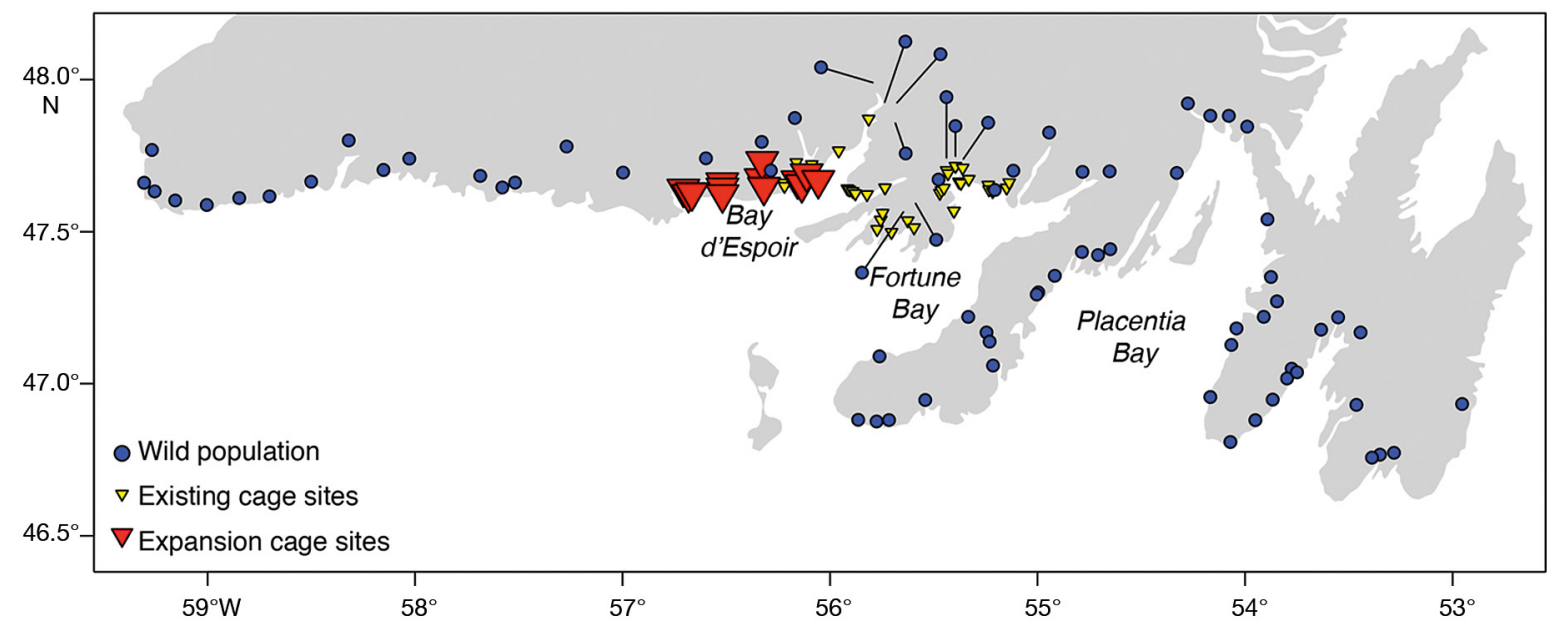

Fig. 1. Southern Newfoundland rivers known to contain wild Atlantic salmon, existing aquaculture sites, and proposed expansion sites 
capees have been detected in rivers throughout the region (Hamoutene et al. 2018, Keyser et al. 2018), and $17 \%$ represents the best information at present. The proportion of escapees that are reproductively mature during freshwater entry has been estimated for the Garnish system in southern Newfoundland (located on the east side of Fortune Bay) as 63\%, calculated using counting fence data for 2015-2017. This is, however, based only on individuals phenotypically identified as escapees (i.e. late escapees) at the counting fence, and, as early escapees could be undetected, this is likely an underestimate. Overall, based on the best available data, we estimate that the proportion of escapees that enter freshwater and mature is $\sim 11 \%$. This is comparable to a value of $15 \%$ currently in use in similar modeling exercises in Iceland (Johannsson et al. 2017).

Two models of dispersal were calculated, one for early escapees (i.e. smolts) and one for late escapees (i.e. adults), and we assumed an equal split between the 2 in absence of data on early escapees. The number of late escapees from a single site that arrive at rivers $\left(E_{G}\right)$ was calculated using Eq. (2), where $P$ is aquaculture production, $S_{G}$ is the escapees per ton of production, and $M$ is the likelihood that an escapee becomes sexually mature and enters freshwater. $\frac{R}{T}$ represents the time period $(R)$ relative to the total time $(T)$ in the cages that an individual could escape, survive, and sexually mature. We estimated this ratio at 0.66 as it is unlikely an escapee would survive beyond this time (i.e. 1 yr) in the wild (Hansen \& Youngson 2010, Hamoutene et al. 2018).

$$
E_{G}=P S_{G} \frac{R}{T} M
$$

The total number of early escapees from a single site that make it to local rivers was calculated using Eq. (3), where $S_{S}$ is the escapees per ton of production, $L$ represents the proportion of smolts that survive at sea in the wild, and $\frac{L_{f}}{L_{W}}$ is the ratio of farmed to wild
smolt survival.

$$
E_{S}=P S_{s} L\left(\frac{L_{f}}{L_{W}}\right)
$$

At present, the marine survival (smolt to adult) of Atlantic salmon in monitored rivers of Newfoundland varies from $\sim 4$ to $8 \%$ (DFO 2018b); therefore, we set a value of $6 \%$ for this exercise. The relative survival of farm to wild smolts was set at 0.37 following Hindar et al. (2006).

To simulate the dispersal of escapees from cage sites to rivers, we used a Weibull distribution shaped by 2 parameters, representing both the width and the shape or skewness of the distribution. To estimate the width of the distribution, or the distance escapees may disperse along the coast, we used a combination of experimental release data (Hamoutene et al. 2018), escapee recaptures (Keyser et al. 2018), and genetic estimates of hybridization for Newfoundland (Sylvester et al. 2018, Wringe et al. 2018). Similarly, Morris et al. (2008) reported escaped farmed salmon occurring in 56 of 62 Canadian rivers within $300 \mathrm{~km}$ of aquaculture operations. We set a maximum distance at $200 \mathrm{~km}$, which is smaller than used elsewhere (i.e. Johannsson et al. 2017), but still larger than both tagging and genetic indications of escapee dispersal in southern Newfoundland. Modifying the shape or skewness of the distribution can allow projections to account for the influence of ocean currents, which can influence distribution patterns (Hansen \& Youngson 2010). Ocean currents in the region are largely wind-driven and predominately from the northeast in winter and spring and southwest in summer and fall. Recent tagging work (Hamoutene et al. 2018) suggests no obvious east or west bias in movements along the coast. Therefore, we used a symmetrical distribution for the dispersal of both early and late escapees. See Johannsson et al. (2017) for further details regarding the spatial dispersal model.

Sensitivity analyses were conducted by varying several parameters separately and examining the resultant number and distribution of escapees in rivers under the proposed expansion scenario. First, the number of escapees per unit harvest was varied from 0.2 to 1.2 fish per ton. Second, we varied the proportion of early to late escapees from all early, equal proportions of both, and all late escapees. Finally, we varied the proportion of late escapees that mature and enter rivers from 0.06 , and 0.11 , and 0.16 .

\section{RESULTS}

\subsection{Individual-based modeling of direct genetic impacts}

Individual-based model simulations allowed trends in population abundance and allele frequency to be examined in response to varying levels of invasion by escaped farmed salmon. The annual levels of invasion were varied from 0 to $100 \%$ of the size of the wild population (500 individuals). All runs stabilized near a wild population size of 500 individuals preinvasion and all levels of invasion ranging from 10 to 


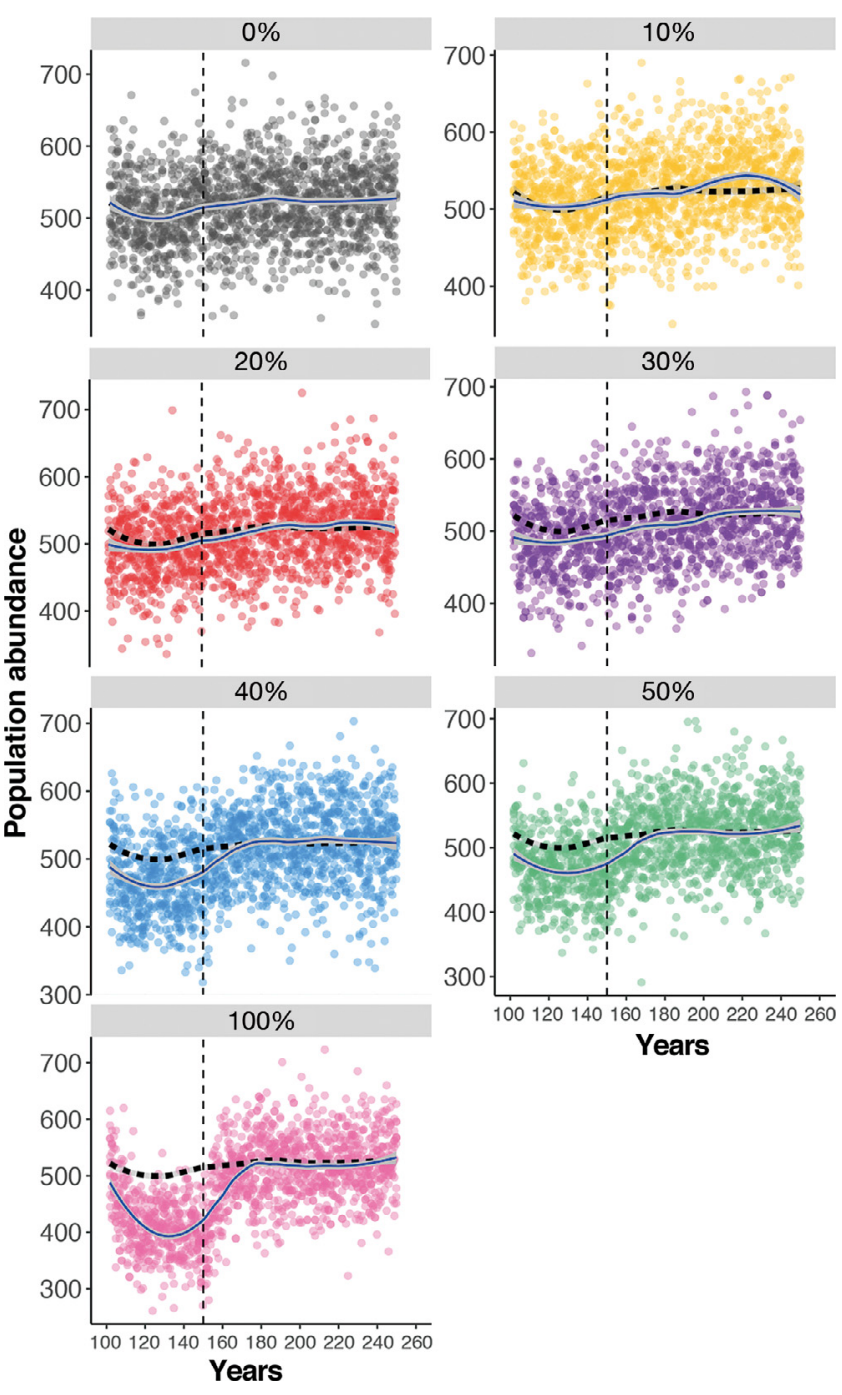

Fig. 2. Demographic changes over time during and following $50 \mathrm{yr}$ of invasion by escaped farmed salmon in southern Newfoundland. All simulations were conducted using IBSEM; see Section 2 and Castellani et al. (2015, 2018), Sylvester et al. (2019) for details. Horizontal dashed line represents the smoothed line of the zero-invasion simulation with $90 \%$ CI (grey shading); vertical dashed line represents the end of simulated invasion of escaped farmed salmon. Solid blue lines represent the smoothed line of 10 replicates shown by the points. Smoothed lines were generated using the geom_smooth function in the R package gg plot2 with the loess regression and a span of 0.5

$100 \%$ displayed evidence of demographic decline (Fig. 2) and genetic change (Fig. 3) in the wild population. Overall, the magnitude of demographic decline and genetic change increased with increasing proportions of farm escapees present when compared to the no invasion scenario (Fig. 4). The magnitude of demographic decline resulting from genetic changes ranged from $\sim 0 \%$ under no invasion to
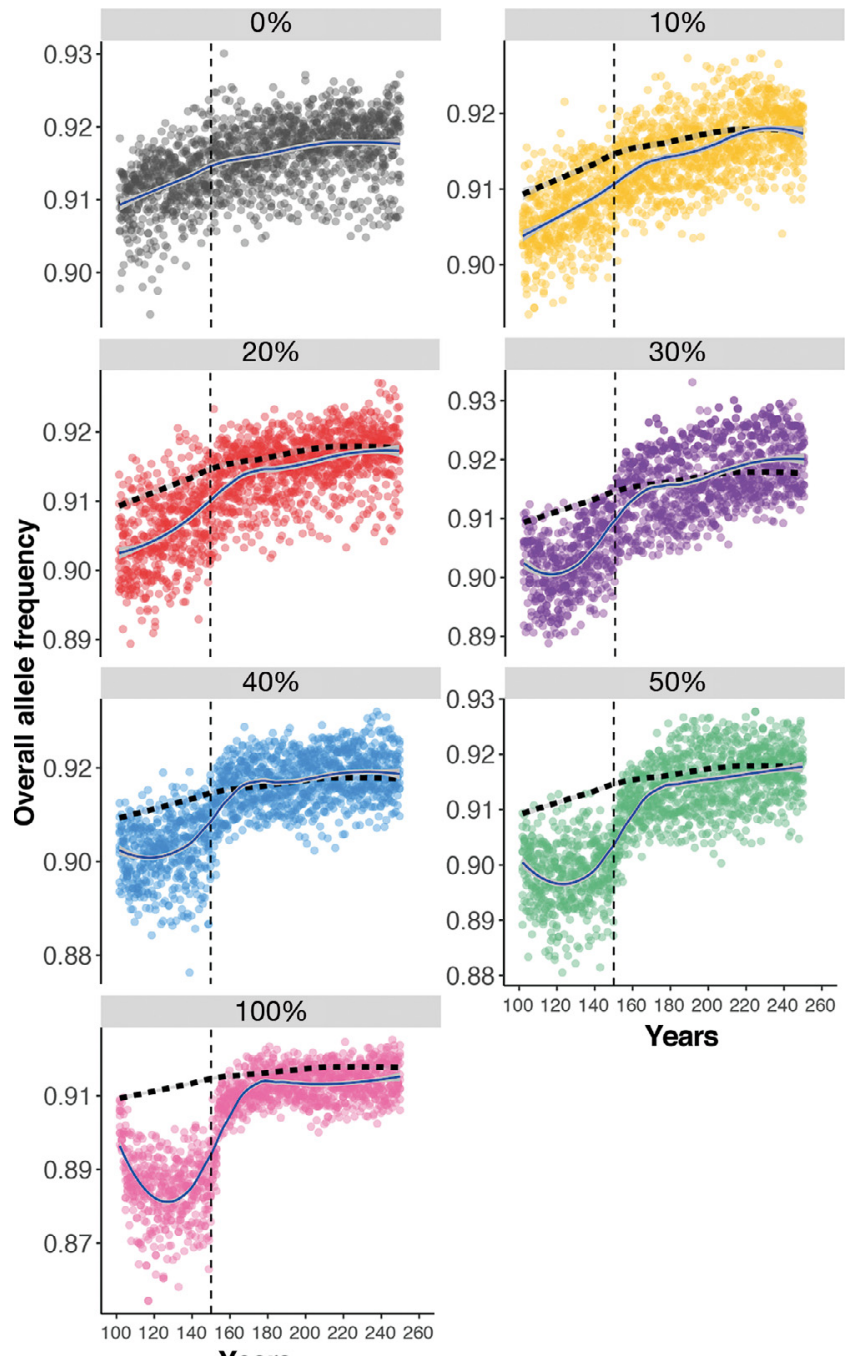

Years

Fig. 3. Changes in overall allele frequency over time during and following $50 \mathrm{yr}$ of invasion by escaped farmed salmon in southern Newfoundland. Wild populations characterized by an allele frequency of 1 and aquaculture populations an allele frequency of 0. See Fig. 2 for further details

25\% decline under $100 \%$ annual invasion (Figs. 2 \& $4)$. The amount of genetic change predicted varied from $<1 \%$ to $\sim 3 \%$ (Figs. $3 \& 4$ ). The time to recover both population size and allele frequency once invasion ceased increased with level of invasion and varied from a few yr to 50+ yr (Figs. $3 \& 4$ ). Overall, the simulations suggest that both demographic decline and genetic change are predicted when the proportion of escapees relative to wild population size equals or exceeds $10 \%$ annually (Fig. 4). As such, a threshold of $10 \%$ escapees relative to the wild population of a given river was used as a threshold for subsequent simulations, see below. Levels of invasion between 1 and $9 \%$ were also examined but were 

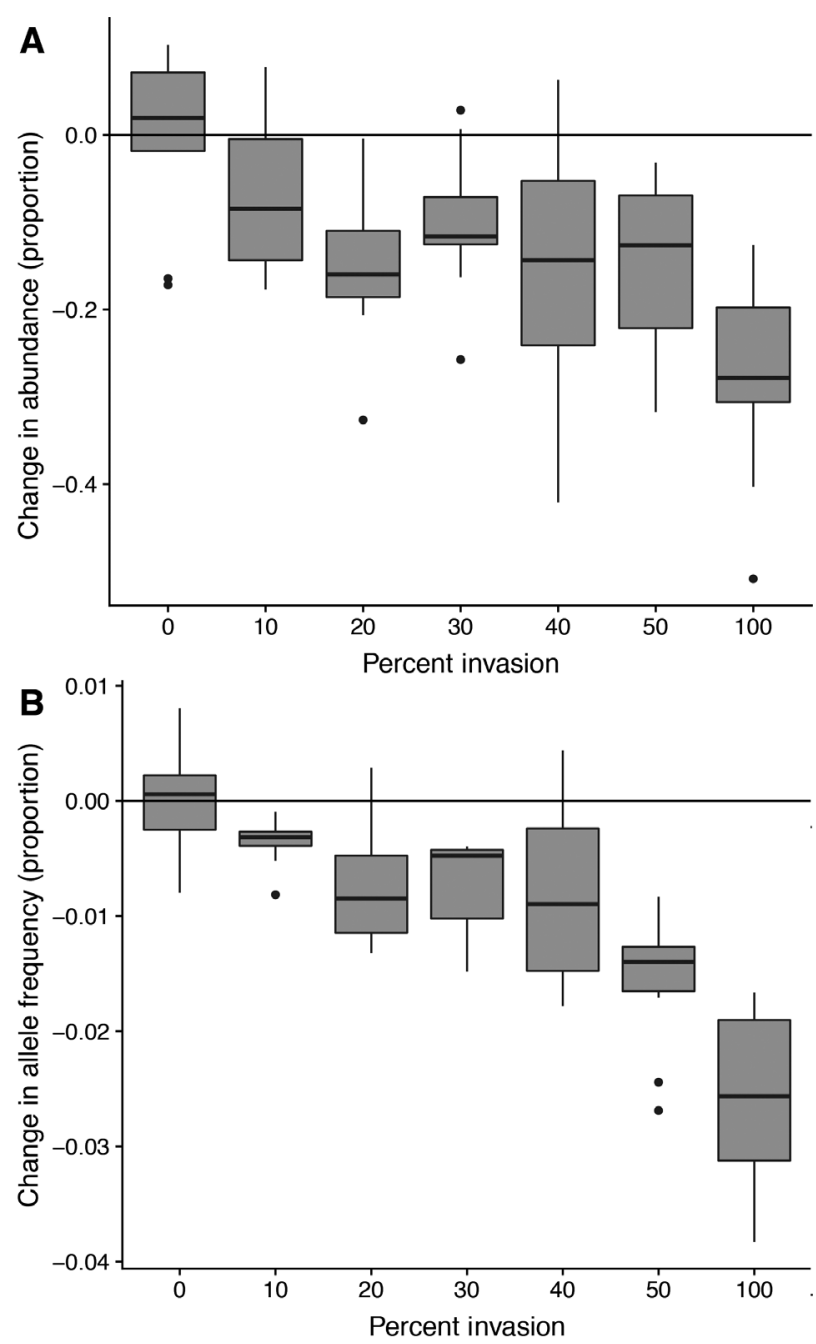

Fig. 4. (A) Magnitude of demographic decline and (B) genetic change observed after $50 \mathrm{yr}$ of invasion by escaped farmed salmon into a wild population. Annual levels of invasion vary from 0 to $100 \%$ of the wild population. Changes were calculated by comparing each scenario (and iteration) against the mean of the zero-invasion scenario at the end of the invasion period. The box limits represent the third (75th percentile) and first (25th percentile) quartile, with whiskers showing the $1.5 \times$ interquartile range. The centre line within boxes represents the median and the points outside the boxes represent outliers. Each boxplot represents results based on 10 iterations for the scenario

highly variable, displayed no consistent trend, and largely did not differ from the zero-invasion scenario.

\subsection{Propagule pressure}

Our calculation of propagule pressure under the current magnitude and distribution of production (Fig. 1) indicates that the areas of highest expected propagule pressure are located at the head of For- tune Bay (Fig. 5). Under the proposed expansion scenario (Fig. 1), the areas of highest propagule pressure are predicted to expand to the west and include the Bay d'Espoir area (Fig. 5), where the propagule pressure is expected to at least double in 7 rivers.

\subsection{Dispersal modeling of escapees}

Under the existing level and distribution of production, the total number of escapees predicted to reach rivers in southern Newfoundland is estimated at 1278 individuals annually. Under this regime, 19 rivers are predicted to meet or exceed the $10 \%$ threshold, with a maximum value of $15.6 \%$ (Fig. 6). Escapees are predicted to occur in all but 11 rivers in Fortune Bay and westwards, with numbers ranging from 1 to 150 escapees per river. Rivers characterized by the largest percentage of escapees are concentrated in Fortune Bay, as well as a few Bay d'Espoir rivers (Fig. 6). Model predictions for the Garnish River suggested 13 escapees annually, which is comparable to the average of 6 escapees detected at the counting fence during the summer months annually.

Under the proposed expansion scenario, the total number of escapees predicted to reach rivers was estimated at 1915 individuals annually, which represented a $49 \%$ increase in the number of escapees predicted in rivers along the coast (Fig. 6). Twenty rivers were predicted to meet or exceed the $10 \%$ threshold, with 8 rivers exceeding $20 \%$ escapees and a maximum value of $24 \%$ (Fig. 6). Escapees were predicted to occur in all but 8 rivers in Fortune Bay and west, with numbers ranging from 1 to 275 escapees per river. Under the proposed expansion, the rivers characterized by the largest number of escapees shift to the head of Bay d'Espoir and to the west (Fig. 6).

We explored the sensitivity of the model predictions to changes in several key parameters. Research using simulated escape events in Norway suggests the actual number of escapees per ton is likely between 0.4 and 0.8 (Skilbrei et al. 2015). We thus varied the number of escapees per ton of harvest from 0.2 to 1.2. The total number of escapees doubled with each doubling of the number of escapees per harvest (Fig. 7A). We also examined how varying the proportion of late or early escapees per ton influenced model predictions (Fig. 7B). Interestingly, we observed a 2.75-fold increase in the percentage of escapees predicted to occur when only late escapees are considered versus early escapees, with estimates ranging from 2860 

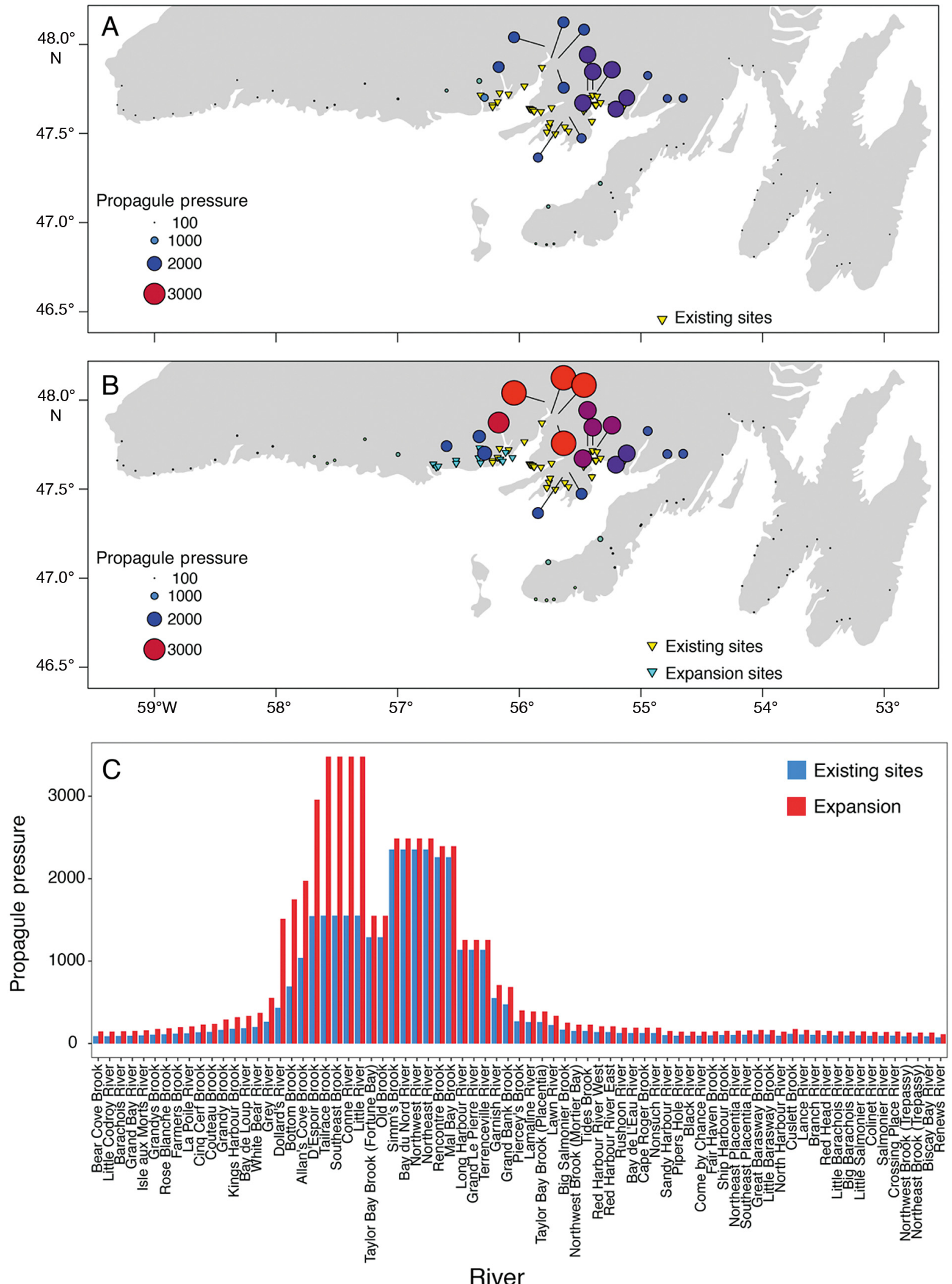

Fig. 5. Propagule pressure calculated following Keyser et al. (2018) for southern Newfoundland under (A,C) the existing production regime and $(B, C)$ the proposed expansion scenario. See Section 2 for details. $(C)$ Rivers are arranged west to east along the $x$-axis 

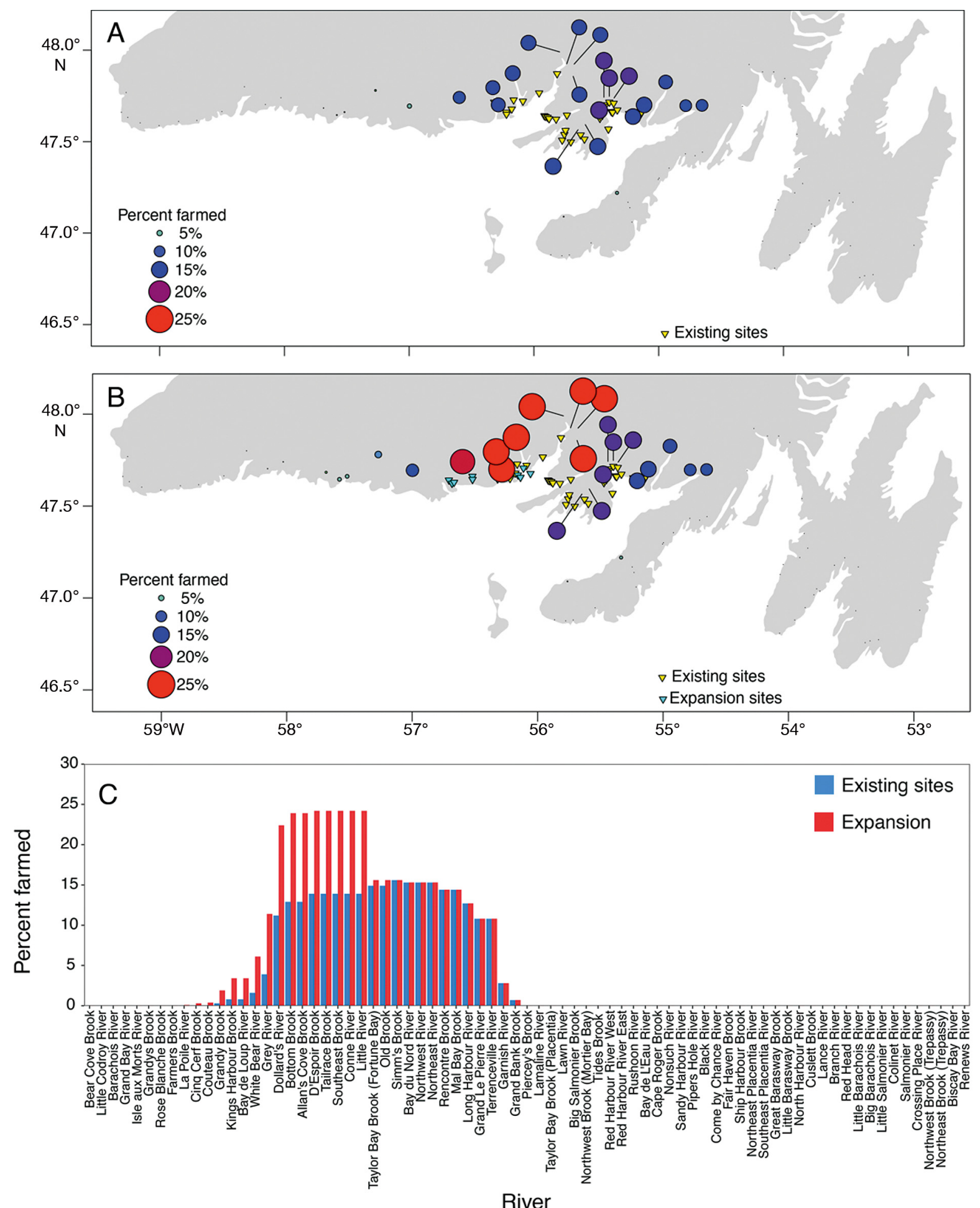

Fig. 6. Predicted spatial distribution and relative percentage of escaped farmed salmon to wild salmon for southern Newfoundland under $(A, C)$ the existing production regime and $(B, C)$ the proposed expansion scenario. See Section 2 for details

(late only) to 970 escapees (early only). For the late escapees only scenario, escapees were also distributed across more locations with higher percentages of escapees compared with only early escapees
(Fig. 7B). Varying the proportion of late escapees resulted in numbers of escapees in rivers ranging from 1265 to 2565 (Fig. 7C). However even under the lowest probability examined (e.g. 0.06), 14 rivers were 

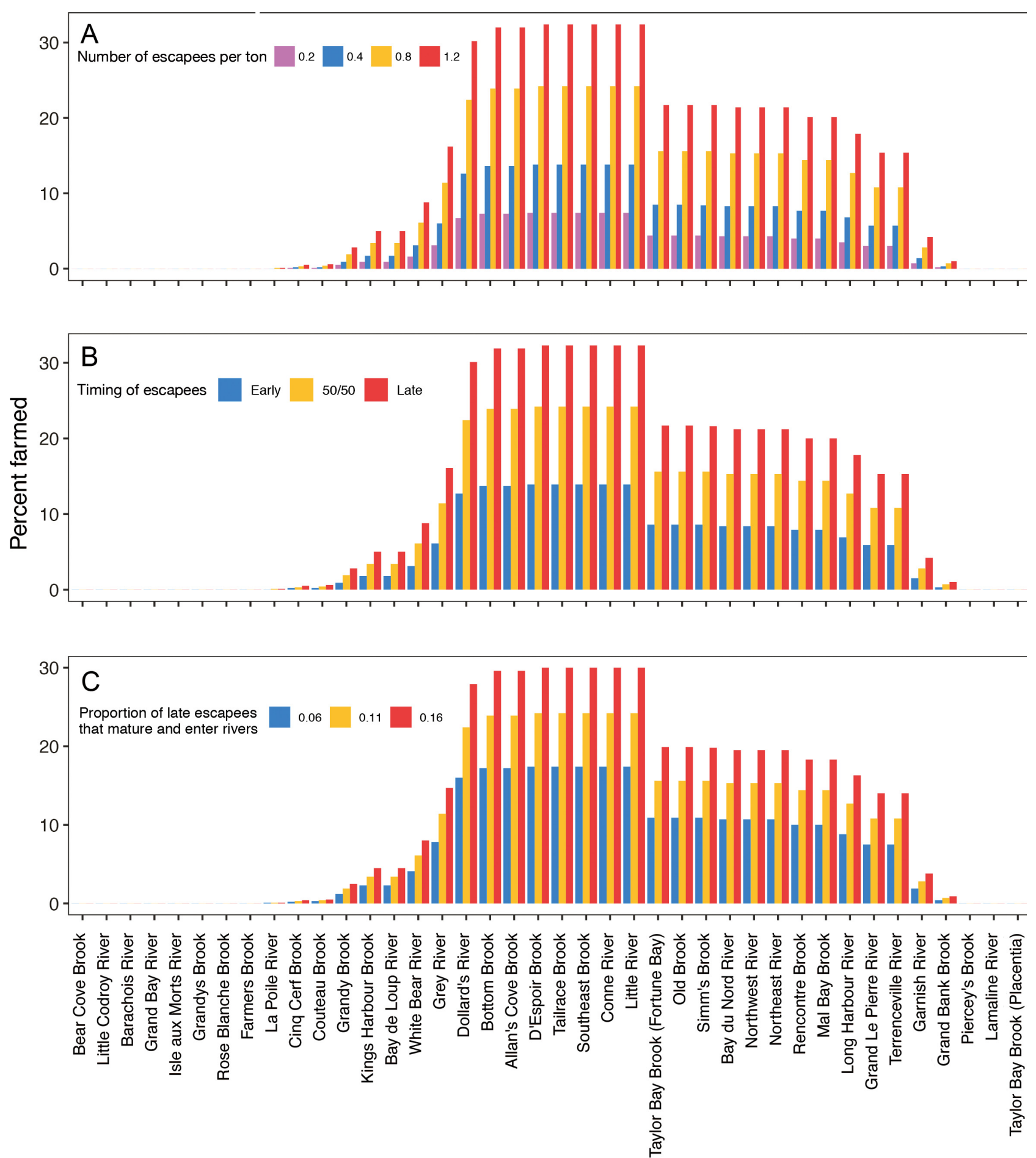

Fig. 7. Predicted relative percentage of escaped farmed salmon to wild salmon in rivers of southern Newfoundland under the proposed expansion scenario, varying (A) the number of escapees per unit harvest, (B) the proportion of early to late escapees, and $(C)$ the proportion of late escapees that mature and enter rivers. See Section 2 for details regarding simulations. Rivers are arranged west to east along the $x$-axis

still predicted to exceed $10 \%$ escapees under the proposed expansion scenario (Fig. 7C).

Modifying the maximum dispersal distance did not significantly alter the number of escapees found in rivers overall; only the distribution of escapees across rivers (Fig. 8). At a maximum dispersal distance of $100 \mathrm{~km}$, escapees were only predicted to occur in 21 rivers with a maximum percentage of $25.4 \%$ es- 


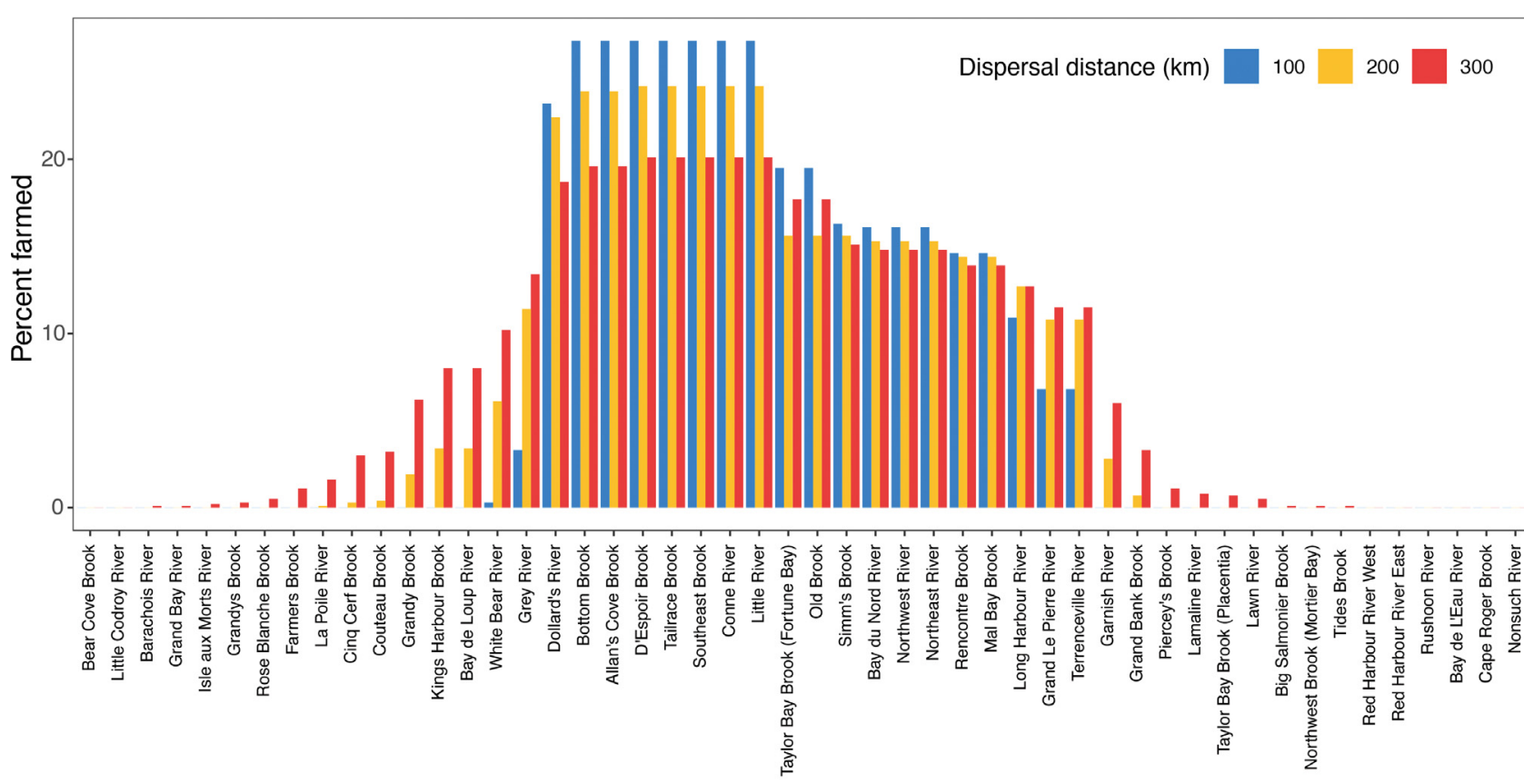

Fig. 8. Predicted relative percentage of escaped farmed salmon to wild salmon in rivers of southern Newfoundland under the proposed expansion scenario, varying the maximum dispersal distance for escapees. See Section 2 for details regarding simulations. Rivers are arranged west to east along the $x$-axis

capees. At a maximum dispersal distance of $200 \mathrm{~km}$, escapees were predicted to occur in 29 rivers with a maximum percentage of $23.3 \%$ escapees (Fig. 8). Finally, at a maximum dispersal distance of $300 \mathrm{~km}$, escapees were predicted to occur in 37 rivers with a maximum percentage of $19.6 \%$ escapees (Fig. 8).

\section{DISCUSSION}

Genetic interactions between wild and escaped Atlantic salmon have been documented both in Europe (Glover et al. 2017) and North America (Bourret et al. 2011, Sylvester et al. 2018, Wringe et al. 2018) and represent a significant threat to the persistence of wild salmon populations where they occur (Forseth et al. 2017). Nonetheless, the ability to incorporate predictions of risk into aquaculture siting advice and management decisions has been limited to date. Our goal was to demonstrate the utility of recently developed model-based approaches (e.g. Castellani et al. 2015, Johannsson et al. 2017) to predict potential genetic interactions resulting from escapees using a proposed site expansion scenario in southern Newfoundland as an example. Our individual-based simulations suggest that as the proportion of escapees within a population increases beyond $10 \%$, both population decline and genetic change are expected, and thus allow an assessment of the risk various levels of escapees pose to wild populations. Our analysis of propagule pressure and simulations of escapee dispersal into southern Newfoundland rivers (estimated population size $\sim 22000$ individuals, COSEWIC 2010) suggest increased numbers of escapees $(49 \%$ or 1.5 fold increase) and westward shifts in the predicted distribution of escapees associated with the proposed expansion scenario. Our results directly build on previous modeling and empirical studies (Hindar et al. 2006, Glover et al. 2017, Castellani et al. 2018, Keyser et al. 2018, Sylvester et al. 2019) and directly illustrate how predictions of genetic impacts from aquaculture site expansion can be used to inform management decisions and salmon conservation.

\subsection{Individual-based model predictions of impact}

Population impacts of hybridization with escaped farmed salmon have been shown to vary (Glover et al. 2017, Sylvester et al. 2018) and, as such, predicting population responses to the presence of escaped farmed salmon remains a challenge. Our individualbased eco-genetic simulations suggest that demographic decline and genetic change are apparent once the percentage of escapees in rivers equals or exceeds $10 \%$, and that the observed impacts in- 
crease with the proportion of escapees. These predictions are consistent with empirical estimates of reduced aquaculture offspring survival (Fleming et al. 2000, McGinnity et al. 2003, Skaala et al. 2012, Sylvester et al. 2019) and reductions in wild population productivity resulting from hybridization with farm escapees (Fleming et al. 2000, Castellani et al. 2018, Sylvester et al. 2019). For example, Fleming et al. (2000) report a reduction of $>30 \%$ in productivity of a wild population experiencing hybridization. The magnitude of the predicted demographic changes observed here varied with the proportion of escapees present in the river, but ranged from $<10 \%$ to $>50 \%$ decline and were generally less than $30 \%$ for most simulations over the modeled $50 \mathrm{yr}$ period. The predicted genetic changes are consistent with both local evidence of hybridization and introgression in the region following escape events (Sylvester et al. 2018, Wringe et al. 2018) and recent studies suggesting significant changes to key life history traits due to introgression (Bolstad et al. 2017, Skaala et al. 2019). As these impacts scale with the proportion of escapees present, the ultimate impact to wild populations experiencing escapees may be significantly greater in small or depressed populations and existing empirical data support this hypothesis (Heino et al. 2015, Sylvester et al. 2018, Wringe et al. 2018).

A significant outcome of the individual-based modeling is the prediction that genetic and demographic impacts are likely when the proportion of escapees in a river equals or exceeds $10 \%$. Estimates of the proportion of escapees occurring in rivers have been used as a management or conservation tool elsewhere and model predictions of population impacts of escapees can directly inform siting decisions and mitigation action. In Norway, extensive summer and autumn surveys for escapees are used to estimate an index of the proportion of escapees in rivers (Svenning et al. 2017, Diserud et al. 2019, Glover et al. 2019). Based on these surveys, the incidence of escapees in rivers is designated as clearly above or below $10 \%$ and used to prioritize rivers for mitigation action such as the active removal of escapees (Glover et al. 2019). Similarly, a recent risk assessment in Iceland opted for a $4 \%$ threshold for the proportion of escapees in rivers to provide a precautionary approach to siting as the industry develops (Johannsson et al. 2017). These values are consistent with both levels of straying in the wild $(<10 \%$, Stabell 1984, Thorstad et al. 2010) and our observations here that demographic and genetic change are likely when the percentage of escapees equals or exceeds $10 \%$. This value of $10 \%$ escapees relative to wild salmon provides a use- ful metric against which to evaluate field detections of escapees and predictions of future impact.

Ultimately, although the best available regional data were used to parameterize the individual-based model, improved empirical estimates of several key parameters may improve these model predictions and any subsequent management advice. The populationspecific life history and environmental data considered here were from the Conne River, which represents the best studied population/river in southern Newfoundland. Although these data are likely representative of the region, additional data from other populations would allow regional variation in demography, life history, and environmental features to be considered in model predictions. Similarly, potential key variables such as stage specific survival of aquaculture escapees and offspring have been shown to be both spatially and temporally variable (Skaala et al. 2019). Moreover, recent work suggests that population outcomes may be highly influenced by differences in the survival of escapees and hybrids (Sylvester et al. 2019) as well as rates of straying among wild populations (Castellani et al. 2018). As such, further refinement of empirical estimates of these interactions is needed to improve predictions of population outcomes. It is also worth noting that we did not vary the level of invasion annually during the invasion period, and although high annual rates of invasion (50-100\%) may be unlikely for large populations, many of the populations under consideration here likely have small population sizes ( $<100$ adults returning annually) for which these levels of invasion seem possible. Previous modeling studies have varied the levels of invasion annually and reported contrasting results, with either greater impacts from intermittent large escape events (Hindar et al. 2006) or from low level continual invasion (Baskett et al. 2013).

\subsection{Predictions of escapee dispersal}

Ultimately the magnitude and spatial extent of hybridization between wild salmon and domestic escapees will be dependent on the number of escapees, the scale of escapee dispersal in the wild, and the size of wild populations. Our use of a simplified dispersal kernel informed by all available data on escapee dispersal patterns suggests that under the existing distribution of production in the region, the head of Fortune Bay is likely to be characterized by the highest numbers of mature escapees entering rivers. Under the proposed expansion plan, the number of escapees is predicted to increase 1.5-fold (49\%), and 
the area with the highest number of mature escapees entering rivers will shift to the head of Bay d'Espoir. This shift is entirely consistent with our estimates of propagule pressure, the proposed increases in production $(\sim 50 \%)$, and the shift in location of dominant production to the area west of Fortune Bay. Although field detections of aquaculture salmon indicate regional as well as season- and size-specific dispersal patterns (Morris et al. 2008, Keyser et al. 2018, Glover et al. 2019), our model results are consistent with the emerging consensus for escapees in Atlantic Canada, suggesting they are usually found in rivers at moderate to small distances (i.e. $10 \mathrm{~s}$ to $100 \mathrm{~s} \mathrm{~km}$ ) from escape locations (Morris et al. 2008, Keyser et al. 2018). These observations are supported by experimental releases conducted by Hamoutene et al. (2018) in southern Newfoundland indicating maximum dispersal distances of $80 \mathrm{~km}$, with most salmon remaining in the embayment of release. Moreover, genetic identification of hybrids following a single escape event in southern Newfoundland detected first generation hybrids at distances of up to $100 \mathrm{~km}$ from the escape event (Sylvester et al. 2018, 2019, Wringe et al. 2018). Similarly, Morris et al. (2008) reported escaped farmed salmon occurring in 56 of 62 maritime rivers within $300 \mathrm{~km}$ of aquaculture operations.

When considering the predicted proportions of escapees to wild individuals, it is important to note that there is uncertainty in both the estimates of predicted escapees and the estimates of wild population size. The estimates of escapees per unit production used here are based on Norwegian statistics, and there is uncertainty as to their applicability to Newfoundland. Also, the estimates of wild population size used here are the best currently available for many of the rivers considered and are based on habitat-abundance associations identified using a larger geographic area. However, as stated above, these estimates may not adequately reflect recent declines in population size that have occurred in southern Newfoundland (COSEWIC 2010, DFO 2013, 2018b). As such, our predictions of the proportions of escapees in wild populations may be underestimated in some instances, particularly in small populations. Improved estimates of wild population size and the presence of escapees for rivers in the region would improve the assessment of genetic and demographic risk. It is also noteworthy that our predicted number of escapees at the Conne River (located at the head of the Bay d'Espoir) under the current production regime significantly exceed detections there to date based on the summer monitoring period. Although escapees and hybrids have been detected in Conne River (Dempson et al. 2004,
Wringe et al. 2018), the proportions have generally been low even following significant escape events. The mechanism for this discrepancy is unknown at this time, but it is possible that escapees are entering the environment undetected, possibly at times outside the limited monitoring period, are being diverted to the adjacent rivers based on flow patterns in the area, or are not surviving.

The dispersal kernels used in our simulations were parameterized to provide predictions consistent with detections of escapees at the Garnish River counting fence, which is the only monitoring facility regularly detecting escapees in the region. Simulating the observed number of escapees at the Garnish River required using a maximum dispersal distance of $200 \mathrm{~km}$. However, this value exceeds existing empirical estimates for the region, and therefore the model may overestimate dispersal potential in some instances. By comparison, our sensitivity analysis indicated that reducing the maximum dispersal distance to $100 \mathrm{~km}$ reduced the spatial scale of impact but increased the number of escapees predicted to occur in the Bay d'Espoir area under the proposed expansion, with 7 rivers predicted to experience $25 \%$ escapees. Also, we assume the influence of ocean currents in the region on the shape of the dispersal kernel is negligible. This assumption is consistent with the dominance of wind-driven flow in the area and existing tagging data of escapees in the region (Hamoutene et al. 2018).

Examinations of the sensitivity of the spatial model results were used to explore the influence of varying several parameters, including the life stage of escapees, the survival and maturity probability of escapees, and the magnitude of escapees per unit harvest produced. In all 3 cases, the number of predicted escapees increased with increased values for these parameters. It is notable that in most scenarios tested, the rivers in the Bay d'Espoir area were predicted to be characterized by $>10 \%$ escapees under the proposed expansion. Overall, our use of sensitivity analyses provides invaluable insight into the scope for uncertainty in our chosen parameters to influence predictions of impact and ultimately demonstrates that our conclusions are generally robust to changes in key parameters.

\section{CONCLUSIONS}

Genetic impacts of escaped farmed salmon on wild populations have been demonstrated in both Canada and Europe (Glover et al. 2017), and escapees have 
been identified as an ongoing threat to the persistence of wild salmon populations (Forseth et al. 2017). Our individual-based population simulations suggest that as the percentage of escapees within a population equals or exceeds $10 \%$, both demographic decline and genetic change are expected, and the magnitude of these changes increases with increasing proportions of escapees present. Model predictions of escapee dispersal under the examined expansion scenario suggest increases and shifts in both the number and distribution of escapees in southern Newfoundland rivers, consistent with estimates of propagule pressure. In future, spatial predictions could be improved with data on escapees in the region, including the number and distribution of escapees in the wild, the proportion of early and late escapees that actually enter freshwater, and the temporal occurrence of escape events across the production cycle. Ultimately, the approaches applied here allow the identification of potential impacts predicted under aquaculture expansion and illustrate how model-based predictions of escapee dispersal and genetic impacts can be used to inform both aquaculture management decisions and wild salmon conservation.

Acknowledgements. The authors thank R. Gregory and T. Kess for comments on this manuscript. Funding was provided through the Fisheries and Oceans Program for Aquaculture Regulatory Research. This work has benefited greatly from a 3 year Canada-EU Galway Statement for the Transatlantic Ocean Research Alliance Working Group on modelling genetic interactions among wild and farm escaped Atlantic Salmon in the North Atlantic, involving participants from 7 countries. The models applied here were evaluated and discussed as part of this working group.

\section{LITERATURE CITED}

Baskett ML, Burgess SC, Waples RS (2013) Assessing strategies to minimize unintended fitness consequences of aquaculture on wild populations. Evol Appl 6:1090-1108

Bolstad GH, Hindar K, Robertsen G, Jonsson B and others (2017) Gene flow from domesticated escapes alters the life history of wild Atlantic salmon. Nat Ecol Evol 1:0124

'Bourret V, O'Reilly PT, Carr JW, Berg PR, Bernatchez L (2011) Temporal change in genetic integrity suggests loss of local adaptation in a wild Atlantic salmon (Salmo salar) population following introgression by farmed escapees. Heredity 106:500-510

Castellani M, Heino M, Gilbey J, Araki H, Svåsand T, Glover KA (2015) IBSEM: An individual-based Atlantic salmon population model. PLOS ONE 10:e0138444

* Castellani M, Heino M, Gilbey J, Araki H, Svåsand T, Glover KA (2018) Modeling fitness changes in wild Atlantic salmon populations faced by spawning intrusion of domesticated escapees. Evol Appl 11:1010-1025

COSEWIC (Committee on the Status of Endangered Wildlife in Canada) (2010) COSEWIC assessment and status report on the Atlantic salmon Salmo salar in Canada. Committee on the Status of Endangered Wildlife in Canada, Ottawa

Dempson JB, Furey G, Bloom M (2004) Status of Atlantic salmon, Salmo salar, in Conne River, SFA 11, Newfoundland, 2003. DFO Can Sci Adv Sec Res Doc 2004/057

DFO (2013) Recovery potential assessment for the south Newfoundland Atlantic salmon (Salmo salar) designatable unit. DFO Can Sci Advis Sec Sci Advis Rep 2012/007,

DFO (2018a) Review of the science associated with the inner Bay of Fundy Atlantic salmon live gene bank and supplementation programs. DFO Can Sci Advis Sec Sci Advis Rep 2018/041

DFO (2018b) Stock assessment of Newfoundland and Labrador Atlantic salmon-2017. DFO Can Sci Advis Sec Sci Advis Rep 2018/38

DFO (2019) 2018 Atlantic salmon in-season review for the Newfoundland and Labrador region. DFO Can Sci Advis Sec Sci Rep 2019/004

* Diserud OH, Fiske P, Sægrov H, Urdal K and others (2019) Escaped farmed Atlantic salmon in Norwegian rivers during 1989-2013. ICES J Mar Sci 76:1140-1150

Fleming IA, Hindar K, Mjølnerød IB, Jonsson B, Balstad T, Lamberg A (2000) Lifetime success and interactions of farm salmon invading a native population. Proc R Soc B 267:1517-1524

Forseth T, Barlaup BT, Finstad B, Fiske P and others (2017) The major threats to Atlantic salmon in Norway. ICES J Mar Sci 74:1496-1513

*Glover KA, Pertoldi C, Besnier F, Wennevik V, Kent MP, Skaala $\varnothing$ (2013) Atlantic salmon populations invaded by farmed escapees: quantifying genetic introgression with a Bayesian approach and SNPs. BMC Genet 14:74

* Glover KA, Solberg MF, McGinnity P, Hindar K and others (2017) Half a century of genetic interaction between farmed and wild Atlantic salmon: status of knowledge and unanswered questions. Fish Fish 18:890-927

Glover KA, Urdal K, Næsje T, Skoglund H and others (2019) Domesticated escapees on the run: the second-generation monitoring programme reports the numbers and proportions of farmed Atlantic salmon in >200 Norwegian rivers annually. ICES J Mar Sci 76:1151-1161

*Hamoutene D, Cote D, Marshall K, Donnet S and others (2018) Spatial and temporal distribution of farmed Atlantic salmon after experimental release from sea cage sites in Newfoundland (Canada). Aquaculture 492:147-156

* Hansen LP, Jacobsen JA (2003) Origin and migration of wild and escaped farmed Atlantic salmon, Salmo salar L., in oceanic areas north of the Faroe Islands. ICES J Mar Sci 60:110-119

*Hansen LP, Youngson AF (2010) Dispersal of large farmed Atlantic salmon, Salmo salar, from simulated escapes at fish farms in Norway and Scotland. Fish Manag Ecol 17: $28-32$

*Hansen LP, Jacobsen JA, Lund RA (1993) High numbers of farmed Atlantic salmon. Salmo salar L., observed in oceanic waters north of the Faroe Islands. Aquacult Res 24:777-781

* Hansen LP, Reddin DG, Lund RA (1997) The incidence of reared Atlantic salmon (Salmo salar L.) of fish farm origin at West Greenland. ICES J Mar Sci 54:152-155

* Heino M, Svåsand T, Wennevik V, Glover KA (2015) Genetic introgression of farmed salmon in native populations: quantifying the relative influence of population size and 
frequency of escapees. Aquacult Environ Interact 6: 185-190

Hindar K, Fleming IA, McGinnity P, Diserud A (2006) Genetic and ecological effects of salmon farming on wild salmon: modelling from experimental results. ICES J Mar Sci 63:1234-1247

IFC International (2012) Offshore mariculture escapes genetic/ecological assessment (OMEGA) model version 1.0 model overview and user guide. August. Seattle, WA. Prepared for NOAA Fisheries, Seattle, WA

Jensen AJ, Karlsson S, Fiske P, Hansen LP, Hindar K, Ostborg GM (2013) Escaped farmed Atlantic salmon grow, migrate and disperse throughout the Arctic Ocean like wild salmon. Aquacult Environ Interact 3:223-229

Jóhannsson R, Guðjónsson S, Steinarsson A, Friðriksson J (2017) Áhættumat vegna mögulegrar erfðablöndunar milli eldislaxa og náttúrulegra laxastofna á Íslandi. Marine and Freshwater Research Institute, Reykjavik

Karlsson S, Diserud OH, Fiske P, Hindar K (2016) Widespread genetic introgression of escaped farmed Atlantic salmon in wild salmon populations. ICES J Mar Sci 73: 2488-2498

Keyser F, Wringe BF, Jeffery NW, Dempson JB, Duffy S, Bradbury IR (2018) Predicting the impacts of escaped farmed Atlantic salmon on wild salmon populations. Can J Fish Aquat Sci 75:506-512

McGinnity P, Stone C, Taggart JB, Cooke D and others (1997) Genetic impact of escaped farmed Atlantic salmon (Salmo salar L.) on native populations: use of DNA profiling to assess freshwater performance of wild, farmed, and hybrid progeny in a natural river environment. ICES J Mar Sci 54:998-1008

McGinnity P, Prodöhl P, Ferguson A, Hynes RA and others (2003) Fitness reduction and potential extinction of wild populations of Atlantic salmon, Salmo salar, as a result of interactions with escaped farm salmon. Proc R Soc B 270: 2443-2450

Morris MRJ, Fraser DJ, Heggelin AJ, Whoriskey FG, Carr JW, O'Neil SF, Hutchings JA (2008) Prevalence and recurrence of escaped farmed Atlantic salmon (Salmo salar) in eastern North American rivers. Can J Fish Aquat Sci 65: 2807-2826

O'Reilly PT, Carr JW, Whoriskey FG, Verspoor E (2006) Detection of European ancestry in escaped farmed Atlantic salmon, Salmo salar L., in the Magaguadavic River and Chamcook Stream, New Brunswick, Canada. ICES J Mar Sci 63:1256-1262

Editorial responsibility: Tim Dempster,

Melbourne, Victoria, Australia
Porter TR, Riche LG, Traverse GR (1974) Catalogue of rivers in insular Newfoundland, Vol D. Data Record Series No. NEW/D-74-9. Resource Development Branch, Fisheries and Marine Service, Newfoundland Region, St. John's

R Development Core Team (2016) R: a language and environment for statistical computing. R Foundation for Statistical Computing, Vienna

Skaala Ø, Glover KA, Barlaup BT, Svåsand T, Besnier F, Hansen MM, Borgstrøm R (2012) Performance of farmed, hybrid, and wild Atlantic salmon (Salmo salar) families in a natural river environment. Can J Fish Aquat Sci 69: 1994-2006

Skaala Ø, Besnier F, Borgstrøm R, Barlaup B and others (2019) An extensive common garden study with domesticated and wild Atlantic salmon in the wild reveals impact on smolt production and shifts in fitness traits. Evol Appl 12:1001-1016

Skilbrei OT, Heino M, Svåsand T (2015) Using simulated escape events to assess the annual numbers and destinies of escaped farmed Atlantic salmon of different life stages from farm sites in Norway. ICES J Mar Sci 72:670-685

Stabell OB (1984) Homing and olfaction in salmonids: A critical review with special reference to the Atlantic salmon. Biol Rev Camb Philos Soc 59:333-388

Svenning MA, Lamberg A, Dempson B, Strand R, Hanssen $\varnothing K$, Fauchald P (2017) Incidence and timing of wild and escaped farmed Atlantic salmon (Salmo salar) in Norwegian rivers inferred from video surveillance monitoring. Ecol Freshwat Fish 26:360-370

* Sylvester EVA, Wringe BF, Duffy SJ, Hamilton LC, Fleming IA, Bradbury IR (2018) Migration effort and wild population size influence the prevalence of hybridization between escaped farmed and wild Atlantic salmon. Aquacult Environ Interact 10:401-411

* Sylvester EVA, Wringe BF, Duffy SJ, Hamilton LC and others (2019) Estimating the relative fitness of escaped farmed salmon offspring in the wild and modeling the consequences of invasion for wild populations. Evol Appl 12:705-717

Thorstad EB, Whoriskey F, Rikardsen AH, Aarestrup K (2010) Aquatic nomads: the life and migrations of the Atlantic salmon. In: Aas, Ø, Einum, S, Klemetsen, A, Skurdal, J (eds) Atlantic salmon ecology. Wiley-Blackwell, Oxford, p 1-32

Wringe BF, Jeffery NW, Stanley RRE, Hamilton LC and others (2018) Extensive hybridization following a large escape of domesticated Atlantic salmon in the Northwest Atlantic. Commun Biol 1:108

Submitted: September 12, 2019; Accepted: November 29, 2019 Proofs received from author(s): February 5, 2020 